\title{
Effect of Aspirin on Reproductive Functions in Male Albino Rats
}

\author{
Oyedeji K.O ${ }^{1}$. Bolarinwa A.F ${ }^{2}$, Adigun A.K. ${ }^{1}$ \\ ${ }^{1}$ Department of Physiology, Faculty of Basic Medical Sciences, Ladoke Akintola University of Technology, \\ P.M.B. 4000, Ogbomoso, Nigeria \\ ${ }^{2}$ Department of physiology, College of Medicine, University of Ibadan, Ibadan, Nigeria
}

\begin{abstract}
Summary: Aspirin is an organic acid (Acetyl chloride and sodium salicylate), used anciently as an anticlotting agent that reduces the risk of clotting diseases, but there is a dearth of information on its effects on androgenic studies histology of the testes, kidneys and livers and reproductions. This study was designed to investigate the effects of aspirin on reproductive parameters and histopathological changes in male albino rats.

Aqueous diluted aspirin was administered orally for 30 days for androgenic and reproductive studies at the dose of $10 \mathrm{mg} / \mathrm{ml} \mathrm{BW}$. Distilled water $(0.05 \mathrm{ml})$ served as control. Testosterone level was assayed using ELISA, semen analysis were done microscopically. Histology of the testis, kidney and liver was done. Data were analysed using Students't-test at $p<0.05$.

Treatment with aspirin $10 \mathrm{mg} / \mathrm{ml} \mathrm{BW}$ caused no significant ( $p>0.05$ ) increases in body weights of treated rats, relative to control. Aspirin $10 \mathrm{mg} / \mathrm{ml} \mathrm{BW}$ caused significant decrease in testosterone levels and sperm count. Aspirin caused no significant changes in sperm viability but significant increase in abnormal sperm morphology. It caused no visible lesion in the germinal epithelium. male albino rats.

These findings revealed that aspirin could cause deleterious effect on the reproductive parameters in Key words: Aspirin, Albino rats, Testosterone, Sperm count.
\end{abstract}

\section{Introduction}

Asprin (Acetylsalicylic acid) is one of the first-line drugs used as an analgesic to relief minor aches and pains, as an antipyretic to reduce fever, and as an anti-inflamatory medication (Gaciong, 2003).

Aspirin has been reported to be effective in reduction of the risk of various cancer, including those of the colon and lung (Moysich et al., 2002). Today, aspirin is one of the most widely used medications in the world, with an estimated 40,00 tones of it being consumed each year (Macdonald, 2002). Aspirin is used longterm, at low doses, to prevent heart attacks, strokes, and blood clot formation in people at high risk for developing blood clot (Lewis et al., 1983). At higher doses, it can cause gastrointestinal ulcers, stomach bleeding and tinnitus in children and adolescent (Macdonald, 2002). Aspirin causes an increased risk of cerebral microbleeds (Pignatelli et al., 2008) as well as Reye's syndrome when given to children or adolescent to treat fever or illnesses.

However, due to scarcity of information from literature on the effect of aspirin on reproductive parameters in male albino rats, these studies therefore aim at investigating the effect of aspirin on these aforementioned parameters.

\section{Experimental Animals.}

\section{Materials And Methods}

Adult male albino rats weighing between $160 \mathrm{~g}$ and $180 \mathrm{~g}$ bred in the Animal House of Physiology Department, LAUTECH, Ogbomoso were used. They were housed under standard laboratory conditions with a 12 hours daylight cycle and had free access to feed and water; they were acclimatized to laboratory conditions for two weeks before the commencement of the experiments. All experiments were carried out in compliance with the recommendations of Helsinki's declaration on guiding principles on care and use of animals.

\section{Drug}

Aspirin capsules (Greenfield Pharm. Ltd) were bought from Jeopat Pharmacy, Ogbomoso, Nigeria.

Three hundred milligram $(300 \mathrm{mg}$ ) of aspirin was dissolved in $30 \mathrm{ml}$ of distilled water to give a concentration of $10 \mathrm{mg} / \mathrm{ml}$.

\section{Experimental Design}

Twelve animals were randomly divided into two groups with each group consisting of six rats. The two groups of rats were subjected to the following oral treatments once a day for 30 days:

Group I rats received $10 \mathrm{mg} / \mathrm{kg}$ BW of aspirin 
Group II rats received $0.5 \mathrm{ml}$ of distilled water as the control group.

Twenty-four hours (day 31) after the last dosing of the two groups, blood samples were collected and the animals were then euthenised by cervical dislocation for semen analysis. Histological preparation of the testes was also carried out.

\section{Body Weight}

Body weight of each rat was monitored on weekly basis.

\section{Collection of Blood Sample}

Blood samples were collected through the medial cantus into EDTA bottles for hormonal assay.

\section{Hormonal Assay}

Plasma samples were assayed for testosterone using the enzyme-linked immunosorbent assay (ELISA) technique using the Fortress kit.

\section{Semen Collection}

The testes were removed along with the epididymides. The caudal epididymides were separated from the testes, blotted with filter papers and lacerated to collect the semen.

\section{Semen Analysis}

Progressive sperm motility: This was done immediately after the semen collection. Semen was squeezed from the caudal epididymis onto a pre-warmed microscope slide $\left(27^{\circ} \mathrm{C}\right)$ and two drops of warm $2.9 \%$ sodium citrate was added, the slide was then covered with a warm cover slip and examined under the microscope using X400 magnification. Ten fields of the microscope were randomly selected and the sperm motility of 10 sperms was assessed on each field. Therefore, the motility of 100 sperms was assessed randomly. Sperms were labelled as motile, sluggish, or immotile. The percentage of motile sperms was defined as the number of motile sperms divided by the total number of counted sperms (i.e. 100) (Mohammad-Reza et al., 2005).

Sperm viability (Life/dead ratio): This was done by adding two drops of warm Eosin/Nigrosin stain to the semen on a pre-warmed slide, a uniform smear was then made and dried with air; the stained slide was immediately examined under the microscope using x400 magnification. The live sperm cells were unstained while the dead sperm cells absorbed the stain. The stained and unstained sperm were counted and the percentage was calculated (Laing, 1979).

Sperm morphology: This was done by adding two drops of warm Walls and Ewas stain (Eosin/Nigrosin stain can also be used) to the semen on a prewarmed slide, a uniform smear was then made and air-dried; the stained slide was immediately examined under the microscope using x400 magnification (Laing, 1979). Five fields of the microscope were randomly selected and the types and number of abnormal spermatozoa were evaluated from the total number of spermatozoa in the five fields; the number of abnormal spermatozoa were expressed as a percentage of the total number of spermatozoa.

Sperm count: This was done by removing the caudal epididymis from the right testes and blotted with filter paper. The caudal epididymis was immersed in $5 \mathrm{ml}$ formol-saline in a graduated test-tube and the volume of fluid displaced was taken as the volume of the epididymis. The caudal epididymis and the $5 \mathrm{ml}$ formol-salline were then poured into a mortar and homogenized into a suspension from which the sperm count was carried out using the improved Neubauer haemocytometer under the microscope.

\section{Testicular Histology}

After weighing the testes, they were immediately fixed in Bouin's fluid for 12 hours and the Bouin's fixative was washed from the samples with $70 \%$ alcohol. The tissues were then cut in slabs of about $0.5 \mathrm{~cm}$ transversely and the tissues were dehydrated by passing through different grades of alcohol: $70 \%$ alcohol for 2 hours, 95\% alcohol for 2 hours, $100 \%$ alcohol for 2 hours, $100 \%$ alcohol for 2 hours and finally $100 \%$ alcohol for 2 hours. The tissues were then cleared to remove the alcohol, the clearing was done for 6 hours using xylene. The tissues were then infilterated in molten Paraffin wax for 2 hours in an oven at $57^{\circ} \mathrm{C}$, thereafter the tissues were embedded. Serial sections were cut using rotary microtone at 5 microns $(5 \mu \mathrm{m})$. The satisfactory ribbons were picked up from a water bath $\left(50^{\circ}-55^{\circ} \mathrm{C}\right)$ with microscope slides that had been coated on one side with egg albumin as an adhesive and the slides were dried in an oven. Each section was deparaffinized in xylene for 1 minute before immersed in absolute alcohol for 1 minute and later in descending grades of alcohol for about 30 seconds each to hydrate it. The slides were then rinsed in water and immersed in alcoholic solution of 
hematoxylin for about 18 minutes. The slides were rinsed in water, then differentiated in $1 \%$ acid alcohol and then put inside a running tapwater to blue and then counterstained in alcoholic eosin for 30 seconds and rinsed in water for a few seconds, before being immersed in 70\%, $90 \%$ and twice in absolute alcohol for 30 seconds each to dehydrate the preparations. The preparations were cleared of alcohol by dipping them in xylene for 1 minute. Each slide was then cleaned, blotted and mounted with DPX and cover slip, and examined under the microscope. Photomicrographs were taken at x40, x100 and x400 magnifications

\section{Statistical Analysis}

The mean and standard error of mean (S.E.M.) were calculated for all values. Comparisons between the control and the treated groups were done using the student's t-test. Differences were considered statistically significant at $\mathrm{p}<0.05$.

\section{Effect on Body Weight}

\section{Results}

Treatment of rats for 30 days with $10 \mathrm{mg} / \mathrm{kg}$ BW of aspirin caused non-significant ( $>>0.05$ ) changes in body weight relative to the control.

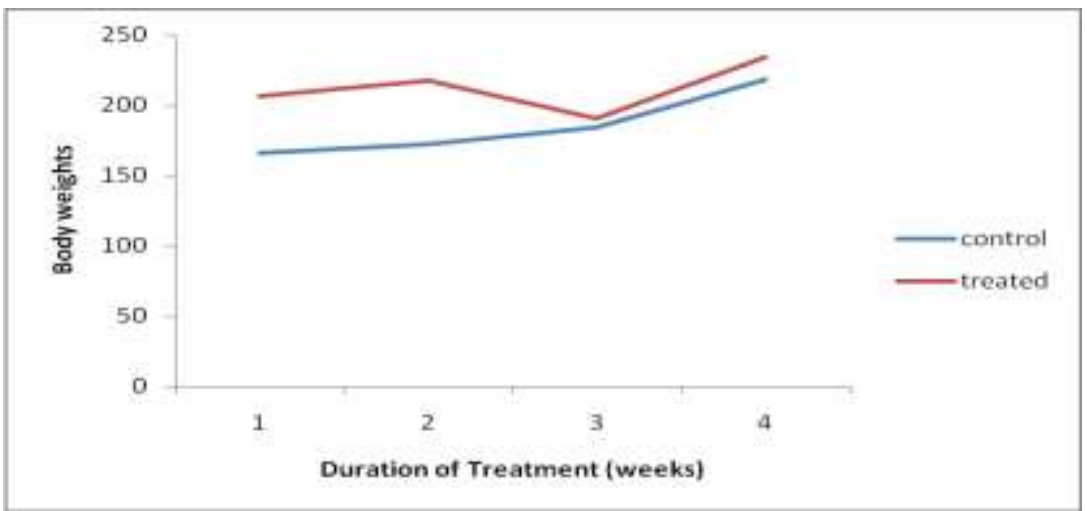

Figure 1: $\quad$ Effects of 30 days (4 weeks) treatment with aspirin on body weight of male rats $(n=6, p>0.05)$

\section{Effect on Hormonal Levels}

Treatment of rats for 30 days with aspirin $(10 \mathrm{mg} / \mathrm{kg} \mathrm{BW})$ caused significant $(\mathrm{p}<0.05)$ decrease in testosterone levels relative to the control.

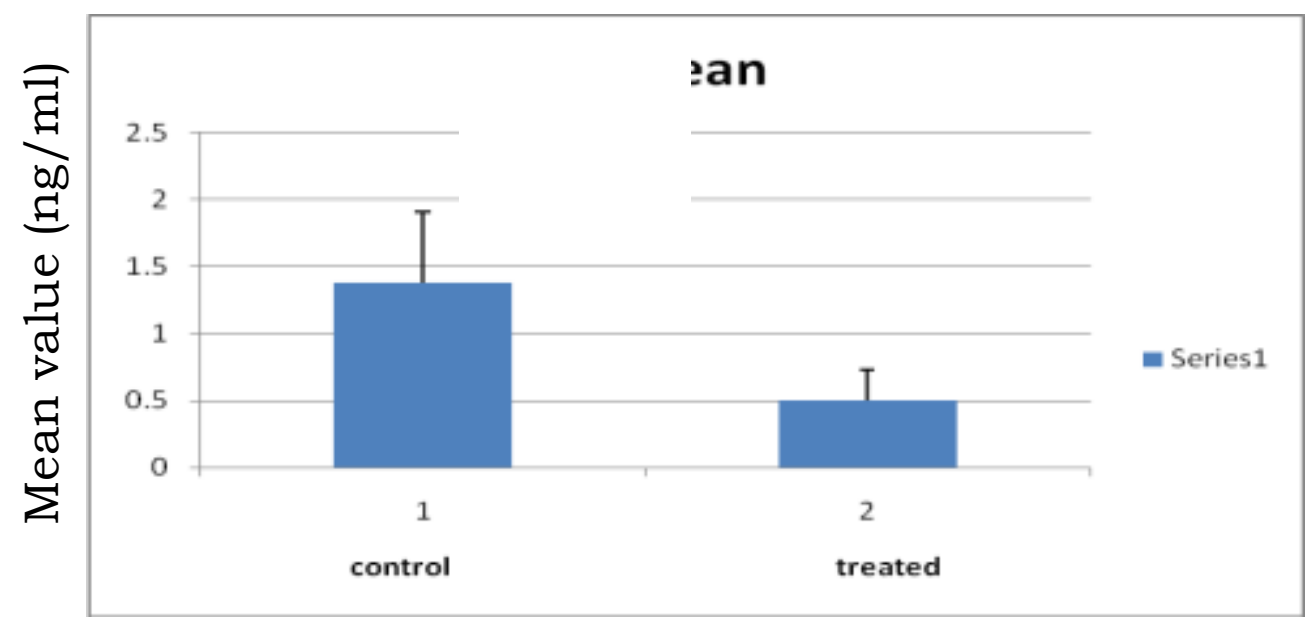

Groups

Figure 2: Effect of 30 days (4 weeks) treatment with aspirin on testosterone levels of male rats $(n=6, * p>0.05)$.

\section{Effect on Sperm Characteristics}

Treatment of rats for 30 days with aspirin $(10 \mathrm{mg} / \mathrm{kg} \mathrm{BW})$ caused significant $(\mathrm{p}<0.05)$ decrease in sperm motility relative to the control. Aspirin $(10 \mathrm{mg} / \mathrm{kg} \mathrm{BW})$ caused non-significant $(\mathrm{p}>0.05)$ decrease in sperm viability (life/dead) but caused significant $(\mathrm{p}<0.05)$ increase in the percentage of abnormal sperm cells. Aspirin also caused significant $(\mathrm{p}<0.05)$ decrease in sperm count. 


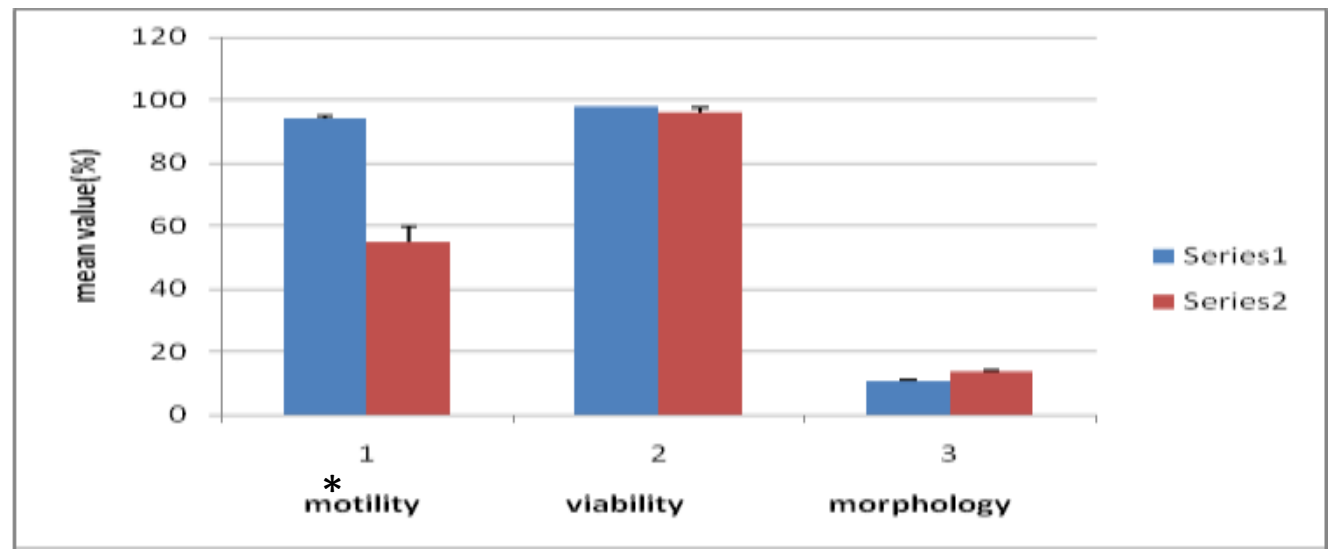

Sperm characteristics

Figure 3: $\quad$ spermogram showing the effects of 30 days treatment with aspirin on sperm characteristics $(\mathrm{n}=6, * \mathrm{p}<0.05)$

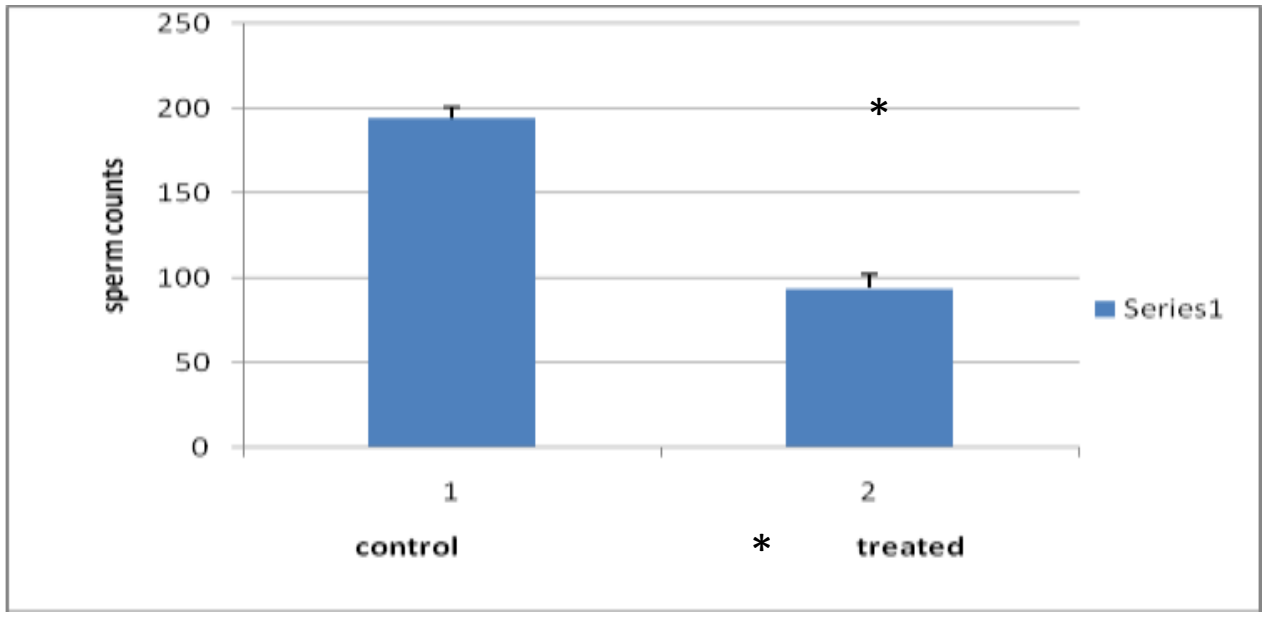

\section{Groups}

Figure 4: $\quad$ Spermogram showing the effects of 30 days treatment with aspirin on $(10 \mathrm{ml} / \mathrm{kgBw})$ sperm count $\left(\mathrm{n}=6,{ }^{*} \mathrm{p}<0.05\right)$

\section{Histopathological Observations}

Rats treated for 30 days with aspirin $(10 \mathrm{mg} / \mathrm{kg} \mathrm{BW})$ presented with normal germinal epithelium with no visible lesion which is similar to what was observed in the control.

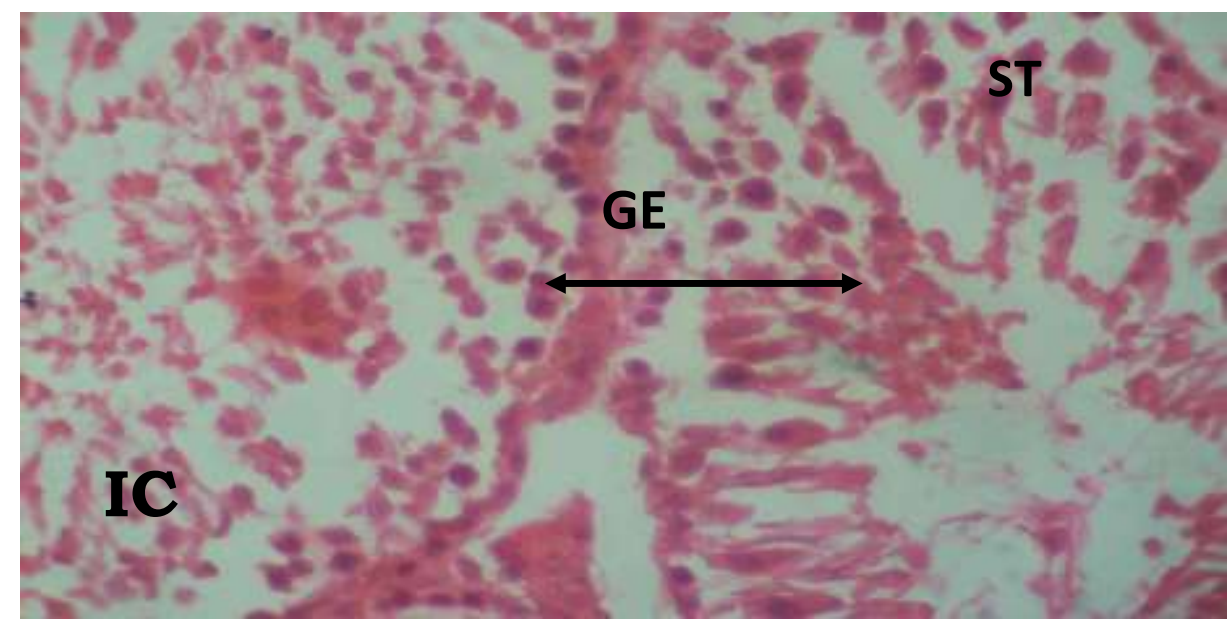

Plate 1: Effect of $0.5 \mathrm{ml}$ distilled water (control) on the testis after treatment of rats for 30 days.

Photomitograph showing normal seminiferous tubules (ST) germinal epithelium (GE) and interstitial cells (IC). 


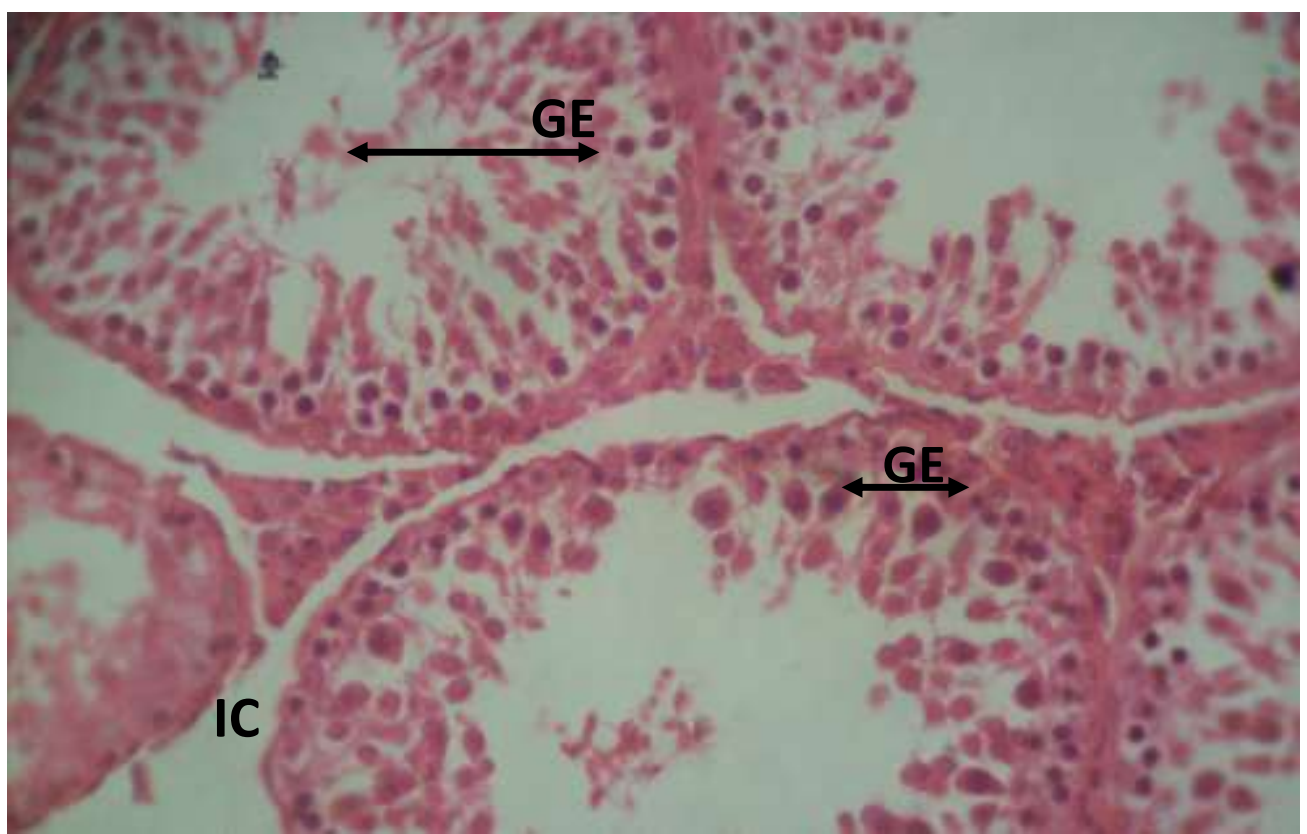

Plate 2: Effect of $10 \mathrm{mg} / \mathrm{kg} \mathrm{BW}$ of aspirin on the testis after treatment of rats for 30 days (X 400). Photomitograph showing normal germinal epithetilium (GE) with no visible lesion.

\section{Discussion}

Aspirin caused non-significant changes in body weight of rats after treatment for 30 days, this suggest that aspirin was not toxic to the animals as well as non-androgenic in nature, since androgens are known to posses anabolic activities. Similar report was given by Gonzales et al. (2006) in rats treated with Lepidium meyenii extracts.

Aspirin caused significant decrease in testosterone levels. Similar report was given by Das et al. (2009) in rats treated with Aegle mermelos extract. This decrease in testosterone levels could indicate that aspirin inhibit the mechanism intervening in the process of hormone synthesis in the Leydig cells.

The andrological results show that treatment of rats for 30 days with aspirin caused significant decrease in sperm motility. Similar report was given by Verma et al. (2002) in rats treated with Sarcostemma acidum extract. This suggests that aspirin was able to permeate the blood-testis barrier with a resultant alteration in the microenvironment of the seminiferous tubules, since it has been reported that the decrease in sperm motility caused by chemical agents was due to their ability to permeate the blood-testis barrier (Baldessarini, 1980) and thus, creating a different microenvironment in the inner part of the wall of the seminiferous tubules from that in the outer part (Bloom and Fawcett, 1975).

Aspirin caused non-significant decrease in sperm viability as well as significant increase in the percentage of morphologicaly abnormal sperm cells in the treated rats. This could be due to the ability of aspirin to either interfere with the spermatogenic processes in the seminiferous tubules, epididymal functions or activities of testosterone on hypothalamic release factor and anterior pituitary secretion of gonadotropins which may result in alteration of spermatogenesis (William, 2000; Bowman and Rand, 1985).

Aspirin caused significant decrease in sperm count of the treated rats which could be as a result of decrease in plasma levels of testosterone since this hormone has been reported to be important in the initiation and maintenance of spermatogenesis (Christensen, 1975). Similar report was given by Krishnamoorthy et al. (2007) in Terminalia chebula extract treated rats.

Rats treated with aspirin presented with normal germinal epithelium with no visible lesion. Similar results were reported by Moundipa et al. (1999) in rats treated with Hibiscus macranthus and Basella alba extracts. This suggests that aspirin had no toxic effect on the exocrine function of the testes.

\section{References}

[1] Baldessarini RJ (1980): In drugs and the treatment of psychiatriod disorders. The pharmacological basis of therapeutics Ed. By Goodman and Gilman. Macmillan Pub. Co. Inc. pp. 301-417.

[2] Bloom W, Fawcett DW (1975): Male reproductive system. In the textbook of Histology. Saunders Company, Philadelphia.

[3] Bowman WC, Rand MJ (1985): The reproductive system and drugs affecting the reproductive systems. Textbook of pharmacology, 2nd edition, 20:1-8.

[4] Christensen AC (1975): Leydig cell: In: Handbook of Physiology, edited by P.O. Greep and E.B. Astwoods. Washington D C American Physiological Society. 
[5] Das UK, De D, Chatterjee K, Mallick C, Bera TK, Ghosh D (2009): Antigonadal effect induced by hydro-methanolic extract of leaf of Aelgle mermelos in male rat: Effect of hCG co-administration. Journal of Medicinal Plants Research Vol. 3(10), Pp728 - 735.

[6] Gaciong Z (2003): The real dimension of analgesic activity of aspirin. Thrombosis Research 110(5-6): $361-4$

[7] Gonzales C, Rubio J, Gasco M, Nieto J, Sandra Y, Gonzales GF (2006): Effect of short-term and long-term treatments with three ecotypes of Lepidium meyenii (MACA) on spermatogenesis in rats. Journal of Ethnnopharmacol. (103), $448-454$.

[8] Krishnamoorthy P, Viathinathan S, Rani V, Bhuvaneswari A (2007): Effect of Terminalia chebula fruit extract on lipid peroxidation and antioxidative system of testis of albino rats. African Jouranl of Biotechnology, Vol. 6 (16), Pp $1888-1891$.

[9] Laing JA (1979): Fertility and infertility in domestic animals. 3rd edition 1979 Bailliere Tindall, a division of Cassell Lt.

[10] Lewis HD, Davis JW, Archibald DG, steinkes WF, Smitherman TC, Doherty JE (1983): Protective effect of aspirin against acute myocardial and death in men with unstable angina. New England Journal of Medicine 309 (7): 396 - 403.

[11] Macdonald S (2002): “Aspirin use to be banned in under 16 year olds". BMJ 325 (1371): 988

[12] Mohammad - Reza P, Farzaneh D, Taherch TK, Zoherb PP (2005): The effects of hydroalcholic extract of Actinidia chinensis on sperm count and motility, and blood levels of estradiol and testosterone in male rats. Achieves of Iranina Medicine, Volume 8, Number 3, 211-216.

[13] Moundipa FP, Kamtchouing, Koueta N, Tantchou J, Foyang NPR, Mbiapo FT (1999): Effects of aqueous extracts of Hibiscus macranthus and Basella alba in mature rat testis function. Journal of ethnopharmacology (65)) $133-139$.

[14] Moysich KB, Menezes RJ, Ronsani A et al. (2002): Regular aspirin use and tung cancer risk. BMC cancer 2:31

[15] Pignatelli P, Di Santo S, Barilla F, Gaudio C, Violi F (2008): Multiple anti-atherosclerotic treatments impair aspirin compliance: effects on aspirin resistance. J. Throm. Heamost. 6 (10): $1832-4$

[16] Verma PK, Sharma A, Annu M, Prachi S, Gupta RS, Joshi SC, Dixit VP (2002): Effect of Sarcostemma acidum stem extract on spermatogenesis in male albino rats. J. Androl. 4(1): $43-47$.

[17] William KW (2000): Hormones and Hormone antagonists. In: Remington, The Science and Practise of Pharmacy, vol 11, 20th edition 77: 1390-1391. 